\title{
Research and Prospect of Urban Comprehensive Disaster Prevention Planning Development in China
}

\author{
Xiaozhuo Wang ${ }^{1,2}$, Zhitao Wang ${ }^{1,2}$, Donghui $\mathrm{Ma}^{1,2}$, Jingyu $\mathrm{Su}^{1,2}$ \\ 1.College of Architecture and Urban Planning, Beijing University of Technology \\ 2.Institute of Earthquake Resistance and Disaster Reduction, Beijing University of Technology \\ Beijing, China \\ 1021564179@qq.com,wzt@bjut.edu.cn, jysu@bjut.edu.cn,mdh@bjut.edu.cn
}

\begin{abstract}
Under the background of the new era of socialism with Chinese characteristics, the urbanization process has continued to accelerate, institutional reforms have steadily advanced, the people's need for a better life is growing and urban security and disaster prevention are also facing new opportunities and challenges. This paper firstly sorts out the development process of China's urban comprehensive disaster prevention planning since the founding of the People's Republic of China, and then further elaborates on the system scope and planning content of China's current urban comprehensive disaster prevention planning. Finally, the vision for the development of comprehensive disaster prevention planning is proposed, which is "Comprehensive, Coordinated and Unified".
\end{abstract}

Keywords-Urban planning on comprehensive disaster resistance and prevention; Development process; Current comprehensive disaster prevention planning system; Planning content; Development outlook

\section{INTRODUCTION}

China's climatic and landforms are complex and diverse, and the ecological environment is fragile. Urban disasters are characterized by numerous disasters, frequent disasters, and serious disaster $\operatorname{losses}^{[1]}$.The Chinese government has always attached great importance to disaster control and management. With the advancement of urbanization, the city is not only a settlement for human survival, but also a high concentration of population, economy, information and industry. Urban safety and disaster prevention has become an important part of the people's demand for a better life in the new era. The longstanding problems of the comprehensive disaster prevention planning system are also urgently needed to be solved, such as the unclear planning scope and the imperfect compilation system.

This paper first expounds the development process of China's urban comprehensive disaster prevention planning, and then draws that "the whole process, the full disaster, the comprehensive" is the inevitable trend of the development of disaster prevention planning, and expounds the current planning system and the content of the preparation, finally explores the development direction of urban comprehensive disaster prevention planning under the new situation.

\section{THE DEVELOPMENT HISTORY OF URBAN COMPREHENSIVE DISASTER PREVENTION PLANNING IN CHINA}

\section{A. The beginning of the founding of the country - Initial development}

At the beginning of the founding of the country, disasters occurred frequently in various places, and the floods were the most serious. The Chinese government proposed and determined the national disaster relief policy, and led the national people to fight against natural disasters. The urban disaster prevention plan was also identified as an integral part of urban planning. However, due to historical conditions, there is no system for the formation of a scientific system ${ }^{[2]}$.

In 1976, the occurrence of the Tangshan earthquake made people realize the importance of urban disaster monitoring and prevention. Later, the relevant documents on earthquake and civil air defense were promulgated, and the urban disaster prevention work was further moved from the local to the whole. The concept of comprehensive urban disaster prevention was gradually formed ${ }^{[3]}$.

\section{B. Reform and opening up - long-term development}

Since the reform and opening up, the establishment of laws and regulations in the field of urban disaster prevention planning has received more attention. Urban disaster prevention work is more rational and pragmatic, and the natural disaster prevention system has been initially established ${ }^{[4]}$.In the 1990 s, China cooperated with the United Nations to launch the International Decade for Disaster Reduction (1990-2000), implemented a series of major disaster reduction projects, and achieved many important results. In 1994, the major project "Basic Research on Urban and Engineering Disaster Reduction" was launched, and Tangshan was selected as one of the demonstration and research cities for comprehensive disaster prevention measures. The practice of urban disaster prevention and reduction has been greatly developed. 
At the beginning of the 21st century, SARS virus spread, snow and ice, earthquakes and other disasters occurred one after another, which made our government deeply aware of the complex diversity of urban disasters and the importance of urban "full process" disaster prevention and mitigation ${ }^{[5]}$. The Urban and Rural Planning Law of the People's Republic of China, which was implemented in 2008, determines that urban disaster prevention and mitigation is a mandatory content in the preparation of urban master plans ${ }^{[6]}$.

\section{New era - Development and Transformation}

In 2014, the first meeting of the Central National Security Committee first proposed the "overall national security concept" and defined "11 security systems", including land security and ecological security, and emphasized the need to step out of a national security road comprehensive and systematic. In March of the same year, the "Organizational Reform Plan of the State Council" was approved, and the establishment of the Ministry of Natural Resources and the Emergency Management Department was clearly established. It is also an important node for the development and reform of urban comprehensive disaster prevention planning. In March 2019, the implementation of the "Urban Comprehensive Disaster Prevention Planning Standards" provided a basic supporting framework for the prevention and contingency of major and catastrophic disasters in the urban planning stage ${ }^{[7]}$.

\section{CHINA'S CURRENT URBAN COMPREHENSIVE DISASTER PREVENTION PLANNING SYSTEM}

China's current comprehensive urban disaster prevention planning has many relevant contents. From the perspective of system scope, urban comprehensive disaster

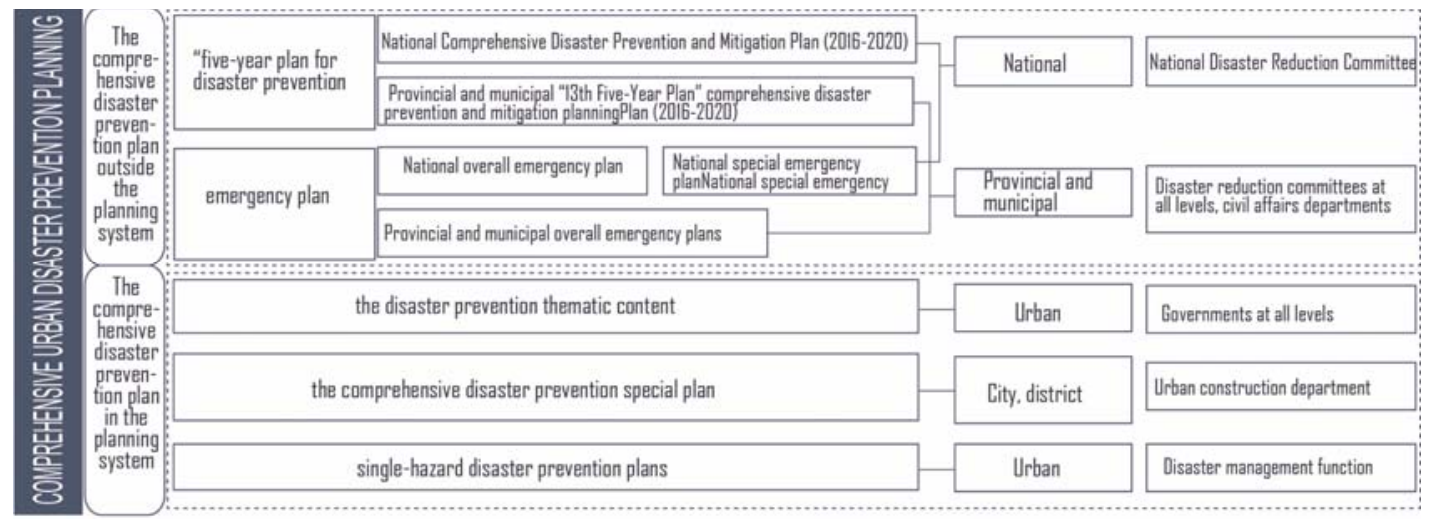

Fig. 1 Urban Integrated Disaster Prevention Planning System

TABLE 1 Urban Integrated Disaster Prevention Planning System

\begin{tabular}{|c|c|c|c|}
\hline & \multicolumn{2}{|c|}{ comprehensive urban disaster prevention planning } & \multirow{2}{*}{$\begin{array}{l}\text { single-hazard disaster } \\
\text { prevention plans }\end{array}$} \\
\hline Classification & $\begin{array}{c}\text { The comprehensive disaster } \\
\text { prevention plan outside the } \\
\text { planning system }\end{array}$ & $\begin{array}{c}\text { The comprehensive disaster } \\
\text { prevention plan in the } \\
\text { planning system }\end{array}$ & \\
\hline Target & \multicolumn{3}{|c|}{$\begin{array}{l}\text { It is consistent in the overall goal and the long-term goal, that is, to ensure the safety of the overall } \\
\text { space of the city. But in terms of phased and regional specific goals, it still differs. }\end{array}$} \\
\hline $\begin{array}{l}\text { Countermeasure } \\
\text { implementation }\end{array}$ & $\begin{array}{l}\text { Management-type countermeasures, } \\
\text { that is, the integration of various } \\
\text { disaster prevention management } \\
\text { powers }\end{array}$ & $\begin{array}{l}\text { Space type disaster prevention } \\
\text { measures }\end{array}$ & $\begin{array}{l}\text { Focusing on engineering- } \\
\text { based countermeasures, } \\
\text { supplemented by space- } \\
\text { based countermeasures }\end{array}$ \\
\hline $\begin{array}{l}\text { Resource } \\
\text { Integration }\end{array}$ & $\begin{array}{l}\text { Space resources, organizational } \\
\text { resources, human resources, financial } \\
\text { resources, material resources, etc. }\end{array}$ & $\begin{array}{l}\text { Emergency response, } \\
\text { evacuation sites, etc. }\end{array}$ & Engineering technology \\
\hline
\end{tabular}

with Chinese characteristics. In 2015, the Central City Work Conference was held, which clarified that urban security is the primary prerequisite for urban development and should strengthen urban safety response capacity building.

In July 2016, President Xi Jinping went to Tangshan to inspect and proposed a new concept of disaster prevention and reduction in the new era, which is "two persistences and three transformations." The "Opinions on Promoting Urban Security Development" in January 2018 further proposed that the establishment of a system of urban security development should be comprehensive, prevention planning can be divided into two levels within the planning system and outside the planning system (Fig. 1 , TABLE 1) ${ }^{[8-9]}$.

The comprehensive disaster prevention plan outside the planning system is represented by the "five-year plan for disaster prevention and mitigation" and the "emergency plan". The plan is based on management-oriented countermeasures, and the disaster prevention resources such as space resources, organization resources and manpower are coordinated and coordinated from the management level. The comprehensive disaster prevention plan in the planning system includes the disaster 
prevention thematic content and the comprehensive disaster prevention special plan ${ }^{[8]}$ in the overall urban planning, mainly based on space-based disaster prevention measures, mainly reflected in the allocation of disaster prevention resources, such as emergency access, Refuge place, etc. In addition, there are also single-hazard disaster prevention plans based on engineering-type countermeasures, such as earthquake-resistant disaster prevention planning, flood control planning, and firefighting planning. The disaster prevention countermeasures are formulated in accordance with the characteristics and risks of the disasters facing the city.

On the whole, China's current comprehensive disaster prevention planning system is complex, and the comprehensive disaster prevention planning inside and outside the planning system overlaps to some extent. In particular, there are overlapping and even contradictory aspects of planning in the planning system. The urban planning system is not closely connected ${ }^{[10]}$, and the main departments of planning and preparation are scattered and comprehensively coordinated ${ }^{[11]}$.

\section{RESEARCH ON THE CONTENTS OF URBAN COMPREHENSIVE DisAster PREVENTION PLANNING IN CHINA}

China's comprehensive urban disaster prevention planning is in a critical period of "from post-disaster relief to pre-disaster prevention, from dealing with a single disaster to coping with comprehensive disaster reduction, and reducing disaster losses to disaster risk reduction". Relevant academic research and planning practices are also continuing, and the research on integrated disaster prevention compilation content is dominant relative to management system and planning system research.

Wang Zhitao proposed that the comprehensive urban disaster prevention plan should be synchronized with the overall urban planning, and provide suggestions from disaster risk assessment, disaster prevention target formulation, and emergency support infrastructure planning. Wang Jiangbo proposed that the comprehensive disaster prevention planning system should reflect the characteristics of "coordination of various departments, multi-hazard planning, multi-risk determination and multifaceted assessment" [2]. Yi Lixin takes Langfang City as an example to divide urban comprehensive disaster prevention planning into six stages: disaster identification, property vulnerability analysis, disaster risk analysis, loss prediction and risk zoning, determination of planning objectives and mitigation measures, and planning ${ }^{[13]}$. Zhang Jianxin proposed that the law should be improved and the information management and technical support system should be strengthened ${ }^{[14]}$.

This paper summarizes and analyzes the previous studies, and concludes that the current urban comprehensive disaster prevention plan mainly has three major contents: "the Identification and Assessment of Disaster Risk- Defining the Disaster Prevention and Mitigation Target - Disaster Prevention Spatial Layout".

\section{A. the Identification and Assessment of Disaster Risk}

Due to the vast territory and diverse terrain of China, the identification of disaster risks varies from place to place. For example, the concentration of the plain urban population and the flatness of the site make the threat of natural disasters greatly reduced, and the proportion of human-induced disasters increases significantly ${ }^{[15]}$. Mountainous cities have complex terrain and ecological sensitivity. The impact of urban disasters and the intensity of disasters are relatively large in plain cities ${ }^{[16-17]}$. Coastal cities are located at the junction of sea and land, and their environment is relatively complex and unstable ${ }^{[18]}$.Urban disasters mainly include earthquakes, tidal disasters, landslides and debris flows, as well as gradual disasters such as shore erosion and land subsidence, which are characterized by clustering and linkage ${ }^{[19]}$.

The disaster risk assessment has been relatively mature. The general approach is to obtain urban safety suitability zoning through urban disaster risk assessment. In the research of evaluation methods, there are mainly mathematical statistics historical disaster data method, fuzzy evaluation method, etc. The more common method is to use disaster risk (R) by three factors: risk $(H)$, exposure (E), Vulnerability (V), the urban land is divided according to the degree of disaster risk, and the corresponding construction strategy is given ${ }^{[20]}$. Under the trend of planning technology renewal reform, the establishment of monitoring and early warning information management systems using new technologies such as cloud computing and big data has also been continuously improved.

\section{B. The goal of comprehensive disaster prevention planning}

The goal of disaster prevention is the important content of planning, and it is also the fundamental compliance of various disaster prevention facilities in disaster prevention planning. It must be coordinated with urban development goals, and must also conform to the urban disaster background and guide the scientific layout of urban disaster prevention space ${ }^{[21]}$.

The current research on urban comprehensive disaster prevention objectives focuses on the importance and necessity of the target system, and content composition. For example, Wang Zhitao believes that urban disaster prevention objectives should be one of the goals that should be achieved in urban master planning [12], Wang Jiangbo proposed The city's comprehensive disaster prevention objectives should be a system that includes social, economic, management, and environmental objectives ${ }^{[2]}$. Gao Rui believes that the objectives of the disaster prevention and mitigation plan should include programmatic overall goals and specific targets for specific disasters. [twenty two]. However, in practice, the determination of urban disaster prevention objectives is either too broad or too detailed ${ }^{[2]}$, and is weaker in connection with later planning and construction.

\section{Layout of disaster prevention space}

The layout of disaster prevention space has been discussed in terms of layout content and mode, space type, and layout mode. In the discussion of disaster prevention space types, most scholars agree that space classification is based on the security level, and scholars from the venue type. From the perspective of the disaster prevention 
space, it is divided into three categories: urban external space, facility building space and underground space ${ }^{[23]}$. It is divided into site type and site type from the perspective of evacuation site form ${ }^{[24]}$.

The research on disaster prevention space focuses on the construction of shelters and passages ${ }^{[25-28]}$. Other facilities such as municipal engineering facilities and disaster prevention facilities are relatively rare, and their layout patterns are mostly related to urban plane morphology and topographical features. For example, the spatial structure of plain urban can be summarized as multi-center spatial mode, checkerboard, circular radiation and axis correlation ${ }^{[29]}$. The emergency channel system is mainly composed of mesh and circle radial, and the shape is relatively regular. . The mountainous city transportation system has relatively poor connectivity after the disaster in the plain city. On the one hand, it hinders the emergency evacuation during the disaster ${ }^{[30]}$. On the other hand, it can use the massively broken and irregular blocks of the mountain roads to construct the green space and use it as an emergency shelter ${ }^{[31]}$. The coastal city disaster prevention measures are mainly represented by the restoration and reconstruction of coastal moisture-proof seawalls and the construction of shelter forests ${ }^{[32-33]}$.

\section{CONCLUSION AND OUTLOOK}

As a huge system of population, economy and industry, the city has complex and dynamic nature, and it has certain vulnerability in disaster prevention. Urban comprehensive disaster prevention is an important guarantee for the normal operation of the city. Since the founding of the People's Republic of China, China's comprehensive urban disaster prevention planning has experienced the development process of "from scratch, from single to comprehensive". China has now entered a transitional period of new era of socialism with Chinese characteristics and high-quality development of urbanization, and institutional reform has steadily advanced. The city's comprehensive disaster prevention plan needs to clarify the new situation, new status, and new requirements, further improve the comprehensiveness, integrity, science, and sustainability, and propose new measures in the planning system, planning content, and planning implementation level, thus establishing a more Comprehensive, comprehensive and coordinated urban comprehensive disaster prevention planning system.

\section{REFERENCES}

[1] Chu Chuheng. "On Urban Comprehensive Disaster Prevention," J. Urban Development Research, issue 3, pp.2-5, 1996.

[2] Wang Jiangbo. "Research on the Compilation Method of Urban Comprehensive Disaster Prevention Planning in China," J. Programmer, vol. 23, issue 1, pp. 53-55, 2007.

[3] Zhang Weiyue, Gao Xiaowang, Zhou Xiyuan, "Li He. Research on Comprehensive Disaster Prevention in Tangshan City," J. Building Science, issue 2,pp. 8-12, 1996.

[4] Li Chen, "Investigation and reflection on China's disaster public crisis management since the founding of the People's Republic of China ," Guangxi Normal University,pp. 16-26,2010.

[5] Liu Jian, “On the Problems and Governance of Modern Urban Crisis Management," J. Economic Research Guide, issue 24,pp. 235-237, 2013.

[6] Gu Linsheng, Zhang Cong, Ma Shuai, "Research on the Compilation of Urban Public Safety Planning in China," J. Modern City Research, vol. 24, issue 5, pp. 14-19, 2009.
[7] Dai Shenzhi, "Urban Comprehensive Disaster Prevention Planning," China Building Industry Press, pp. 31-36, 2011.

[8] He Lei, Dai Shenzhi, Song Yan. "American Experience in the Compilation and Evaluation of Urban Comprehensive Disaster Prevention Planning and Its Enlightenment to China," J. Journal of Planning, issue 5, pp. 87-94, 2011.

[9] Zhou Xiyuan, Su Jingyu, Guo Xiaodong, et al. "Discussion and prospects of comprehensive urban disaster prevention planning ," Urban Planning Annual Meeting. pp. 986-990, 2004.

[10] Chen Hong, Dai Shenzhi. "New Exploration of Urban Comprehensive Disaster Prevention Planning System and Management System," J. Modern City Research, vol. 28, issue 7,pp. 116-120, 2013.

[11] Wang Zhitao, Su Jingyu. "Some Thoughts on Comprehensive Disaster Prevention in Urban Master Planning," 2013 China Urban Planning Annual Conference. Pp. 1-8, 2013.

[12] Yi Lixin, Chen Shijie, Wang Xiaorong, et al. "Research on Urban Comprehensive Disaster Prevention and Mitigation Planning Method-Taking Langfang City as an Example," J. Chinese Journal of Safety Science, vol. 18,issue 12, pp. 11, 2008.

[13] Zhang Jianxin. "International Comparison of Urban Comprehensive Disaster Prevention and Mitigation Planning," J. Economic and Social Systems Comparison, issue 2, pp. 171-174, 2009.

[14] Dai Ruoyu. "Research on urban disaster prevention and avoidance green space planning method in the North Plain Plain ," pp. 32-33.

[15] Tang Bangxing, Liu Suqing, Liu Shijian. "Mountain Disasters and Their Prevention and Control in China. Mountain Research, "vol. 14, issue 2, pp. 103-109, 1996.

[16] Jiang Wei, Xu Pengzhu, Xu Gang. "Analysis of vulnerability of natural disasters in China's mountainous areas, mountain resources development and sustainable development. ," Chengdu University of Science and Technology Press, pp. 238-242, 1997.

[17] Li Xiangran. Main types, "characteristics and disaster prevention countermeasures of environmental geological disasters in coasta cities," J. Journal of China Geological Disaster Prevention and Control, issue 2,pp. 92-94, 1997.

[18] Feng Xiangyuan, Gao Wei, Zhang Chi, et al. "Research on coastal city disaster risk assessment from the perspective of comprehensive disaster prevention planning___ Taking Tianjin Binhai New Area as an example," 2016 China Urban Planning Annual Meeting.

[19] Wang Zhitao, Su Jingyu, Wang Fei. "Research on disaster prevention planning of mountain cities based on risk control ," Expert Forum on Sustainable Development of Mountainous Cities and Towns. pp. 472-480, 2013.

[20] Wang Xiaozhuo, Wang Zhitao. "Comprehensive disaster prevention planning research adapted to urban master plan ," 2018 China Urban Planning Annual Meeting. pp. 4-5, 2018.

[21] Gao Rui, Yan Wenbo. "Discussion on the factors of disaster prevention and reduction in urban planning ," J. Sichuan Cement, issue 11,pp. 104, 2017.

[22] Chen Zhilong, Xu Yongping, Guo Dongjun, et al. "Exploration and Practice of Integrated Disaster Prevention Spatial Planning in Urban and Rural Overall Planning: Taking Nanjing as an Example ,"China Urban Planning Annual Meeting. pp. 4220-4221, 2009.

[23] Dai Shenzhi, He Lei, Shu Wei. "Analysis of the Planning and Construction of Shanghai Emergency Shelter Sites," J. Shanghai Urban Planning, issue 4,pp. 40-43, 2013.

[24] Zhou Tiejun, Zhao Zaixu. "Implications of Taiwan Disaster Prevention System and Planning," J. International Urban Planning,vol. 30,issue 6,pp. 93-99, 2015.

[25] Shi Liang. "Planning and Construction of Beijing Earthquake Evacuation System ," China Urban Planning Annual Meeting. pp. 5036-5037, 2011.

[26] Chen Guangqing, Bi Yurui, Fan Jiping, et al. "Preparation of Urban Comprehensive Disaster Prevention and Public Safety Planning," J. Security, issue 1,pp. 19-22, 2008.

[27] Ding Lin, Zhai Guofang, Zhang Xueyuan, et al. "Research on the Planning of Earthquake Evacuation Sites in Urban Master Planning," J. Programmer, vol. 29, issue 8, pp. 33-37, 2013.

[28] Wang Jianguo, Yang Junyan. "Research on the Theory and Method of Overall Urban Design in Ping Prototype City_ A Case Study of Zhengzhou,” J. City Planning, vol. 41,issue 5,pp. 9-19, 2017. 
[29] Deng Yuyang, Shi Yujie. "Research on Design Strategy of Public Open Space for Disaster Prevention in Mountainous Cities," J. Sichuan Building Materials, vol. 43,issue 1,pp. 35-37, 2017.

[30] Sun Zhong, Yun Yingxia. "Research on Integrated Disaster Prevention Planning of Small Mountain Cities Based on Smart Technology_ Taking the Downtown Area of Wugang as an Example," J. Architecture and Culture, issue 8,pp. 211-213, 2017.

[31] Su Shanjun. "Research on planning strategy for disaster prevention and mitigation in urban water networks ," Suzhou Institute of Science and Technology,pp. 10-17, 2013.

[33] Qiao Jiguo, "Zhan Huaming, Long Jiangping, et al. Natural disaster risk analysis of coastal sea-related projects in Tianjin," J. Chinese Journal of Geological Hazard and Control, vol 23,issue 4,pp. 5359,2012 